\title{
Survival Analysis Survival from testicular cancer in England and Wales up to 2001
}

\author{
U Nur', B Rachet', E Mitry², N Cooper ${ }^{3}$ and MP Coleman*,I \\ 'Cancer Research UK Cancer Survival Group, Non-Communicable Disease Epidemiology Unit, Department of Epidemiology and Population Health, \\ London School of Hygiene and Tropical Medicine, Keppel Street, London WCIE 7HT, UK; '² Département d'Hépatogastroentérologie et Oncologie \\ Digestive, Centre Hospitalo-Universitaire Ambroise-Paré, 9 avenue Charles de Gaulle, F-92 100 Boulogne, France; '3ocial and Health Analysis and \\ Reporting Division, Office for National Statistics (Room FG/I I 4), I Myddelton Street, London ECIR IUW, UK
}

British Journal of Cancer (2008) 99, S80-S82. doi:I0.1038/sj.bjc.6604597 www.bjcancer.com

Published online 23 September 2008

(c) 2008 Cancer Research UK

Testicular cancer has a peak incidence at around 30 years of age, and it is the most common cancer in men under 35 years of age, accounting for a third of all cancers in that age range (Adami et al, 1994). The age distribution is unusual among adult malignancies, with almost $70 \%$ of cases arising in men under 40 years of age, and only about $2 \%$ in men over 70 years of age. Incidence has increased steadily in many developed countries over the last 50 years, including the United Kingdom (Coleman et al, 1993; Richiardi et al, 2004). In men under 50 years of age, incidence has risen almost two-fold in England and Wales in the last 30 years, but the increase has been much smaller among older men (Quinn et al, 2001).

Age-standardised mortality was 1 per 100000 per year during the 1950 s, and it rose slightly during the 1960s and 1970s. Advances in the treatment of testicular cancer since the 1960s have had a dramatic effect on survival (Coleman et al, 1999), and men born during the 1950s and 1960s had substantially lower testicular cancer mortality in the late 1970s and early 1980s than earlier birth cohorts, despite the substantial rise in incidence (Quinn et al, 2001).

Cryptorchidism is one of the few known risk factors (Richiardi et al, 2002). A positive family history also carries a higher risk, but vasectomy has not been shown to increase risk (Møller et al, 1994).

Most testicular cancers are germ cell tumours, either seminoma or non-seminoma. Seminomas arise from the sperm-producing testicular germ cells, whereas non-seminoma germ cell tumours include teratoma, choriocarcinoma and yolk sac tumours. Seminomas are treated by surgical removal of the affected testicle (orchiectomy) and adjuvant radiotherapy. Surgical treatment is also effective with early stage teratomas. Orchiectomy alone cures around $80 \%$ of testicular cancer patients (Dearnaley et al, 2006).

We analysed survival patterns for 18605 men diagnosed with testicular cancer aged 15-99 years in England and Wales during 1986-1999 and followed up to 31 December 2001. Less than 5\% of tumour records had to be excluded from analysis: $2 \%$ because the vital status was not known when data were extracted for analysis, less than $2 \%$ because the testicular cancer either followed or was synchronous with another primary malignancy, and about $1 \%$ because the date of diagnosis was the same as the date of death ('zero survival'). Virtually all the tumours in the last category will have been registered solely from a death certificate, from which the date of diagnosis is unavailable, as very few men would be

*Correspondence: Professor MP Coleman;

E-mail: michel.coleman@Ishtm.ac.uk expected to have died on the day of diagnosis, but the two categories could not be reliably distinguished in the national data.

In total, $54 \%$ of tumours were seminomas, and $29 \%$ teratomas, similar to the proportions seen in the late 1980s (50 and 30\%). Rare morphologic types included choriocarcinoma, trophoblastic teratoma (1\%), Leydig cell tumour $(0.3 \%)$ and a few Sertoli cell tumours. Although cryptorchidism is a known risk factor, less than $1 \%$ of tumours were recorded as having arisen in an undescended testis.

\section{SURVIVAL TRENDS}

For men diagnosed during 1986-1990, relative survival was $96 \%$ at 1 year after diagnosis and $91 \%$ at both 5 and 10 years. Survival has risen further with time, so that for men diagnosed during 19961999, relative survival had reached $98 \%$ at 1 year after diagnosis and $97 \%$ at 5 years (Table 1, Figure 1). Ten-year survival was effectively the same as 5-year survival.

After adjustment for deprivation, the average increase every 5 years was $0.5 \%$ for 1 -year survival and $1 \%$ for 5 -year survival. These trends are not statistically significant, but the small increases in 1-, 5- and 10-year survival were consistent across three time periods.

Short-term prediction of survival up to 10 years, derived from hybrid analysis (Brenner and Rachet, 2004) of the conditional survival probabilities actually observed among men alive at some point during 2000-2001, suggests that survival will not increase much further in the near future (Table 1). If the most recently observed survival patterns were to persist unchanged for the rest of the decade, men diagnosed in the first few years of the 21 st century may expect 10-year relative survival rates that approach $96 \%$.

Survival rose substantially for older men during the 1990s, and the huge decline in survival with age became less marked. Thus, 5year relative survival was over $90 \%$ for men diagnosed under the age of 50 during the decade $1986-1995$, but less than $70 \%$ for men aged 70-79 years, and less than $40 \%$ for elderly men (80-99 years). For men aged 80-99 years diagnosed during 1996-1999, however, 5-year survival had risen to $55 \%$ (data not tabulated).

\section{DEPRIVATION}

For men diagnosed during 1986-1990, relative survival up to 10 years after diagnosis was significantly lower, by $3-5 \%$, among 
Table I Trends in relative survival (\%) by time since diagnosis and calendar period of diagnosis: England and Wales, adults ( $15-99$ years) diagnosed during 1986-1999 and followed up to 2001

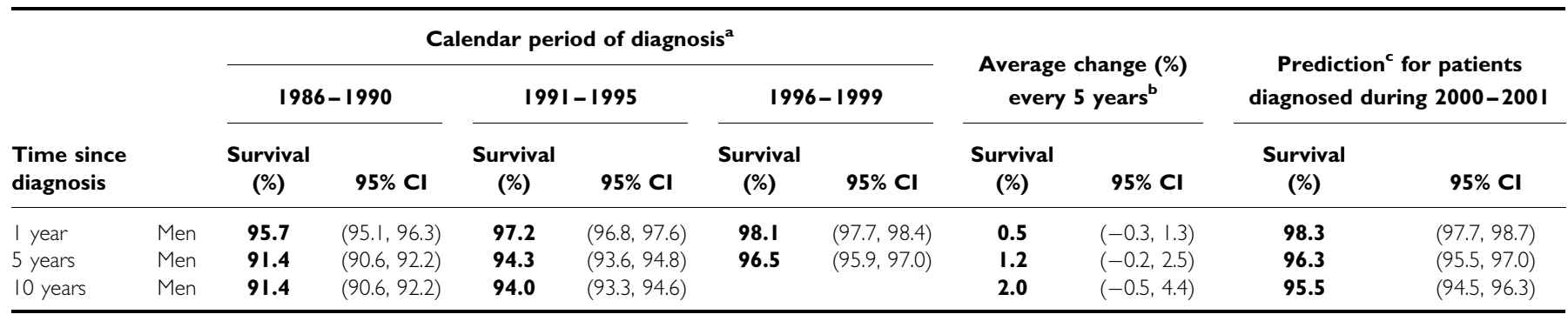

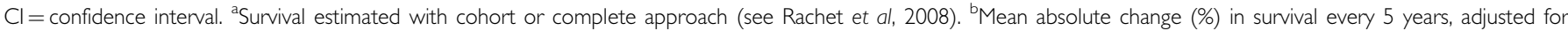
deprivation (see Rachet et al, 2008). 'Survival estimated with hybrid approach (see Rachet et al, 2008).

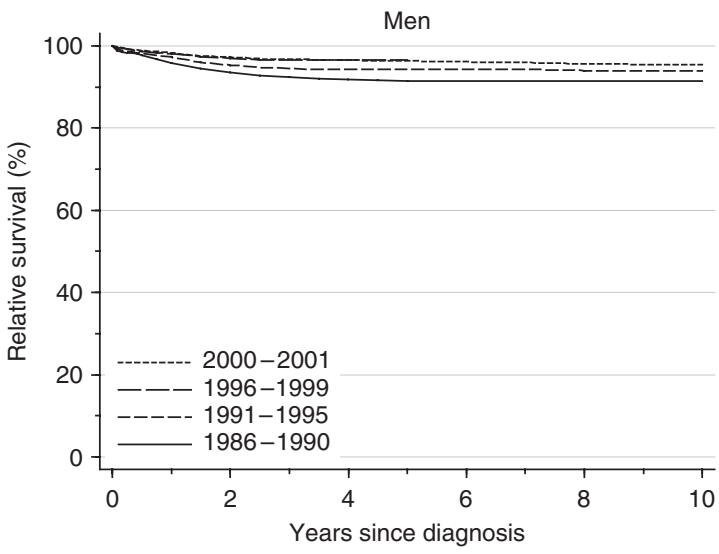

Figure I Relative survival (\%) up to 10 years after diagnosis by calendar period of diagnosis: England and Wales, adults (15-99 years) diagnosed during 1986-1999 and followed up to 200I. Survival estimated with cohort or complete approach (1986-1990, 1991-1995, 1996-1999) or hybrid approach (2000-200I) (see Rachet et al, 2008).

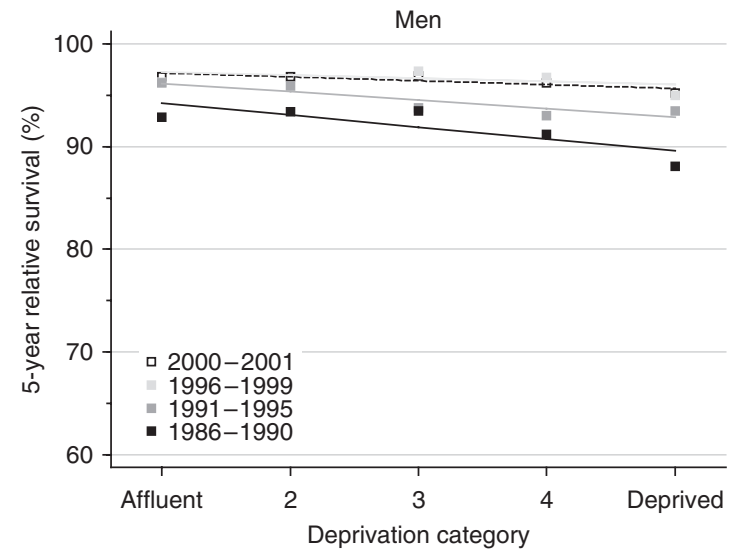

Figure 2 Trends in the deprivation gap in 5-year relative survival (\%) by calendar period of diagnosis: England and Wales, adults (15-99 years) diagnosed during 1986-1999 and followed up to 2001 .

Table 2 Trends in the deprivation gap in relative survival (\%) by time since diagnosis and calendar period of diagnosis: England and Wales, adults (I5-99 years) diagnosed during 1986- 1999 and followed up to 200 I

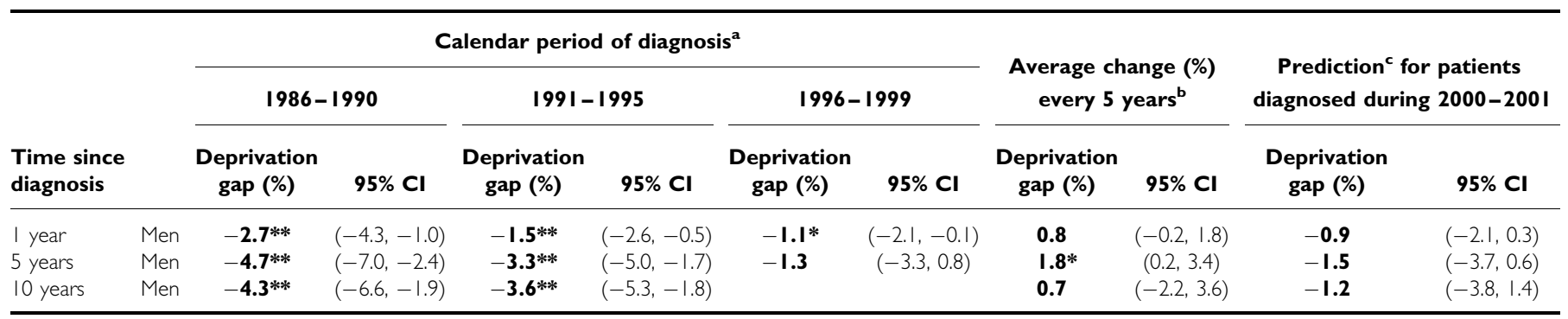

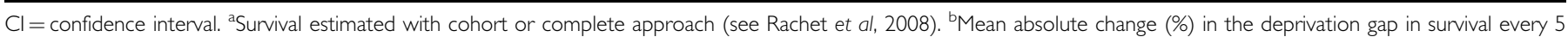
years, adjusted for the underlying trend in survival (see Rachet et al, 2008). 'Survival estimated with hybrid approach (see Rachet et al, 2008). *P<0.05; ** $P<0.01$.

those in the most deprived group than those in the most affluent group (Table 2, Figure 2). By the late 1990s, this deprivation gap in survival at 1, 5 and 10 years had fallen to as little as $1 \%$, and it was only of borderline significance for 1-year survival.

Short-term predictions, based on hybrid analysis of the probabilities observed during 2000-2001, suggest that the deprivation gradient will remain small, of the order of $-1 \%$ (Table 2 ).

\section{COMMENT}

Survival from testicular cancer is the highest for any malignancy among adult males in England and Wales.
The gain in survival over the last 20 years has been little short of remarkable. One-year and five-year survival for men diagnosed in England and Wales during the early 1970s was already 82 and $69 \%$, respectively, but it rose to 95 and $89 \%$, respectively, for men diagnosed in the early 1980s, just a decade later (Coleman et al, 1999). The data reported here show that for men diagnosed in the late 1990s, short-term survival was already approaching the theoretical maximum of $100 \%$, and even longer-term survival exceeded 95\%, whereas period analysis suggests that the increase is likely to continue, albeit more slowly.

The increase in survival among the oldest men is not statistically significant, and it concerns only a small minority of cases, but it 
may be that the very high survival attained in younger men has led to treatment of curative intent being offered to even the oldest men with testicular cancer.

Relative survival at 10 years is now virtually identical to that at 5 years, which itself is already more than $95 \%$. This indicates that, among men who survive 5 years, there is virtually no further excess mortality over that of men in the general population, after adjustment for age and deprivation. In other words, the data provide strong public health evidence that 5-year survivors of testicular cancer are now virtually all 'cured', because, taken as a group, their mortality is no different from that of their peers in the general population.

Coherence of national trends in incidence, survival and mortality since the 1970s is striking. Despite rapidly rising incidence, survival has risen and mortality has continued to fall. This provides convincing evidence of the nation-wide impact of the addition of platinum-based chemotherapy in the 1970s to early diagnosis, surgery and radiotherapy.

\section{REFERENCES}

Adami H-O, Bergström R, Möhner M, Zatonski W, Storm HH, Ekbom A, Tretli S, Teppo L, Ziegler H, Rahu M, Gurevicius R, Stengrevics A (1994) Testicular cancer in nine northern European countries. Int J Cancer 59: $33-38$

Brenner H, Rachet B (2004) Hybrid analysis for up-to-date long-term survival rates in cancer registries with delayed recording of incident cases. Eur J Cancer 40: 2494-2501

Coleman MP, Babb P, Damiecki P, Grosclaude PC, Honjo S, Jones J, Knerer G, Pitard A, Quinn MJ, Sloggett A, De Stavola BL (1999) Cancer Survival Trends in England and Wales 1971-1995: Deprivation and NHS Region. Studies on Medical and Population Subjects No. 61. The Stationery Office: London

Coleman MP, Estève J, Damiecki P, Arslan A, Renard H (1993) Trends in Cancer Incidence and Mortality (IARC Scientific Publications No. 121). International Agency for Research on Cancer: Lyon

Dearnaley DP, Huddart RA, Horwich A (2006) Regular review: managing testicular cancer. Br Med J 322: $1583-1588$
Despite the fact that relative survival was very high for men in all socioeconomic groups combined, there was still a significant socioeconomic gradient in survival. This is so even after adjustment for socioeconomic differences in the background risk of death by the use of life tables that are specific for each socioeconomic group.

The trend in overall survival now approaches $100 \%$, and the deprivation gap in survival has fallen commensurately, from $13 \%$ or more for men diagnosed during the early 1970 s to less than $5 \%$ for men diagnosed during the late 1990s. This narrowing of the deprivation gap appears to reflect a 'ceiling' effect, as there is little room for any further increase in relative survival among the most affluent group. Survival for the most affluent men diagnosed most recently approaches $100 \%$.

Despite the unquestionably dramatic improvement in survival, men in the most deprived categories still only attain the relative survival of the most affluent men with a time lag of at least 5 calendar years.
Møller H, Knudsen LB, Lynge E (1994) Risk of testicular cancer after vasectomy: cohort study of over 73000 men. Br Med J 309: 295-299

Quinn MJ, Babb P, Brock A, Kirby L, Jones J (2001) Cancer Trends in England and Wales 1950-1999. Studies on Medical and Population Subjects No. 66. Office for National Statistics: London

Rachet B, Woods LM, Mitry E, Riga M, Cooper N, Quinn MJ, Steward J, Brenner H, Estève J, Sullivan R, Coleman MP (2008) Cancer survival in England and Wales at the end of the 20th century. $\mathrm{Br} J$ Cancer 99 (Suppl 1): S2-S10

Richiardi L, Akre O, Bellocco R, Ekbom A (2002) Perinatal determinants of germ-cell testicular cancer in relation to histological subtypes. Br J Cancer 87: 545-550

Richiardi L, Bellocco R, Adami H-O, Torrång A, Barlow L, Hakulinen T, Rahu M, Stengrevics A, Storm HH, Tretli S, Kurtinaitis J, Tyczynski JE, Akre O (2004) Testicular cancer incidence in eight northern European countries: secular and recent trends. Cancer Epidemiol Biomarkers Prev 13: $2157-2166$ 